\title{
Group mentoring for junior Medical students: perceptions of mentees and mentors
}

\author{
Percepções de estudantes de Medicina e de \\ mentores sobre um programa de tutoria \\ (mentoring) desenvolvido em grupos
}

PALAVRAS-CHAVE

- Estudantes de Medicina

- Docentes de Medicina

- Mentores

- Educação médica
Recebido em: 07/03/2009 Aprovado em: 04/04/2009

Maria de Fátima Aveiro Colares ${ }^{\mathrm{I}}$

Margaret de Castro ${ }^{\mathrm{I}}$

Cristiane Martins Peres ${ }^{\mathrm{I}}$

Afonso Diniz Costa Passos ${ }^{\mathrm{I}}$

José Fernando de Castro Figueiredo ${ }^{\mathrm{I}}$

Maria de Lourdes Veronese Rodrigues ${ }^{\mathrm{I}}$

Luiz Ernesto de Almeida Troncon ${ }^{\mathrm{I}}$

\begin{abstract}
A B S T R A C T
Entering medical school can be associated with a number of difficulties that can hinder students' performance. Mentoring programs are designed to help students circumvent difficulties and improve their learning and personal development. The current study aimed to evaluate the perceptions of both students and mentors regarding a recently introduced, group-based mentoring program designed to support first-year students. After one year of regular meetings, students and mentors' perceptions of the program were assessed by means of structured questionnaires. Response content categories were identified through multiple readings. Both regular attendees and non-participating students had positive opinions about the program. Mentors were highly satisfied at having participated and acknowledged that the program has been useful not only for assisting students, but also for fostering their own personal and professional development. In conclusion, the group-based mentoring program is feasible and can elicit positive views from both mentors and students. In addition, faculty members' participation as mentors can also be beneficial, since the program appears to contribute to their own personal and professional development.
\end{abstract}

\section{R E S U M O}

O ingressante na escola médica pode encontrar dificuldades variadas, que afetam seu desempenho. Programas de apoio com mentores podem servir para auxiliar os estudantes e favorecer seu desenvolvimento pessoal e acadêmico. Neste trabalho avaliamos as percepções de estudantes e de mentores sobre um programa de apoio baseado em grupos e planejado para apoiar estudantes ingressantes. Após um ano de funcionamento regular do programa, as percepções dos estudantes e dos mentores sobre o programa foram avaliadas utilizando questionários estruturados, cuja análise permitiu estabelecer categorias de conteúdo das respostas. Tanto os estudantes que participaram regularmente do programa, como os que não haviam participado expressaram opiniões positivas sobre o programa. Os mentores expressaram alto grau de satisfação em participar do programa e opinaram que o programa vem sendo útil também para auxiliar na formação docente. Concluímos que o programa de apoio ao estudante ingressante, baseado em grupos que operam ao redor de mentores, é viável e efetivo no auxílio ao estudante e pode também contribuir para a formação e o desenvolvimento dos docentes e médicos que participam como mentores. 


\section{INTRODUCTION}

Entering medical school can be associated with a number of difficulties that can hinder students' performance and personal development. Recently admitted medical students routinely face different types of pressure, such as the need to adapt to a new environment and create a social network. New students also have to cope with the stressful nature of medical training ${ }^{1,2}$, dealing with and assimilating vast amounts of scientific content in the first years of medical school. In many countries, students are admitted into undergraduate medical training when they are still just teenagers, thus making them particularly vulnerable to such difficulties. Therefore, many medical schools have implemented student support and counseling systems ${ }^{3-11}$. However, many of the proposed programs work mainly on an individual basis and therefore assist only a limited share of students.

In recent decades, much emphasis has been placed on mentoring in undergraduate medical education ${ }^{9-14}$, which may be structured or informal ${ }^{10,15}$, designed for personal or academic development, and made available to the entire student body or merely to underrepresented minorities ${ }^{16}$. Nevertheless, knowledge of students' and mentors' perceptions towards mentoring programs is still limited, since opinions from non-participating students have not often been elicited, and many studies fail to report on the effect participation as mentors has on faculty members.

At our institution, the Ribeirão Preto School of Medicine in the State of São Paulo, Brazil, a group-based, elective mentoring program aimed at supporting first-year medical students and fostering their personal development was recently introduced and has slowly gained increasing student adherence. The present study describes the findings concerning evaluation of motivational aspects and perceptions of the program by students and mentors who participated in regular group meetings for at least one academic year. For students, we compared responses by regular attendees to those of classmates who either did not enroll in the program or only attended meetings occasionally.

\section{METHODS}

\section{Setting}

The Ribeirão Preto School of Medicine is located on a campus of the University of São Paulo in Southeast Brazil. Faculty members are highly qualified, and the vast majority, including those in clinical departments, work fulltime for the institution. Although they are highly committed to academic duties, the amount of individual time devoted to clinical, research, and administrative work is generally more than that dedicated to teaching. Personal contact with students is thus limited, and anonymity is a matter of in- creasing concern. Each year the medical school receives 100 incoming students aged 17-19 years, who enter shortly after finishing high school. The current curriculum is rather traditional and comprises two years of basic sciences, one semester (third year) of pre-clinical disciplines, and three semesters (third and fourth years) of clinical disciplines. The two final years (fifth and sixth years) are spent in internships programs in major clinical areas, such as Internal Medicine, General Surgery, Pediatrics, Obstetrics and Gynecology, and Community Medicine.

\section{The mentoring program}

For nearly two decades, the institution has maintained a formal counseling system for individual, on-demand support for medical students, including a psychologist and educationalist ${ }^{3}$. The perception that such assistance could be extended to larger groups of students and also be more effective in preventing individual problems prompted the introduction of the mentoring program. The program aimed to assist recently admitted first-year medical students. Following a successful experience in the first medical school of the same university ${ }^{9}$, a group-based, holistic mentoring model was adopted ${ }^{17}$, in which mentoring was devised as a way not only of providing emotional support, but also of fostering personal and professional development. A group-based scheme was proposed, so that students could establish personal contact with classmates and share their views and experiences with peers, besides connecting with faculty members and staff physicians acting as mentors. Students enrolled voluntarily (as an extracurricular activity) and were randomly assigned to mentoring groups, with regularly scheduled meetings (at least every other week). Mentoring groups consisted of 6-8 junior students plus the mentor, who was assisted by one or two senior students especially recruited on the basis of their interest in improving student conditions. Mentors were also recruited on a voluntary basis from faculty and medical staff and trained by a supervisory committee consisting of the former support team and a small group of senior faculty members with experience in student affairs. Inclusion criteria were motivation, schedule availability, and regular participation as teachers in the undergraduate medical program. Mentor training aimed primarily to provide a clear understanding of the program's main objectives, as well as to clarify the mentor's role as group facilitator and role model. Mentors were also expected to offer individual personal support and counseling outside the group activities, whenever required. The professional development component was designed as programmed discussions of special themes, such as medicine as a career choice, aspects of physician-patient relationships, the medical workplace, ethical issues, 
etc. Regular monthly meetings with the supervisory committee assured that mentors were assisted in dealing with personal or group difficulties, as well as receiving feedback regarding their roles. Mentors also received regularly selected texts on the students' development, which were discussed with members of the supervisory committee.

\section{Study design}

After participating in regular group meetings for at least one academic year, students and mentors' perceptions of the program were assessed through a cross-sectional, descriptive study with qualitative data collected by means of structured questionnaires. At the time data were collected, according to the supervisory committee, 50 of the 100 first-year students were regularly attending the meetings. All first-year students $(\mathrm{N}=100)$ were invited to answer a written questionnaire containing demographic items, degree of participation in the mentoring program, and open questions on: a) overall perception of the program; $b$ ) motivation to participate; and c) reasons for not participating. Students were also invited to express criticism or free opinions, as well as to present comments and suggestions for program improvement whenever pertinent. Responses from students reporting regular attendance (at least one meeting per month) were compared to those from peers who either did not enroll in the program or only attended the meetings occasionally (fewer than two meetings per year).

All mentors $(\mathrm{N}=10)$ involved in the program received an e-mail requesting them to answer a structured questionnaire containing open questions on the following: a) overall perception of the program; b) motivation for participating;c) perceived gains from regular participation; and d) perceived problems related to the mentoring program activities.

Individual responses to the open questions by both students and mentors were analyzed qualitatively. Response content categories were identified through multiple readings. All individual answers were included, even those expressed by a single respondent.

\section{RESULTS}

\section{Student response}

A total of 74 questionnaires were returned, including 20/50 from regular attendees and 41/50 from non-participants.

Concerning overall perception of the program, all respondents from the participant subgroup were explicitly positive and expressed agreement with the program's objectives and support for maintaining it. Nevertheless, three participants expressed opinions that "the proposal is still vague..." and that "the meetings need better organization..." Twenty-nine of 41 non-participating students also expres- sed positive perceptions, including five who reported that non-participation was due exclusively to lack of time. The remaining non-participating students expressed lack of information on the mentoring program and the perception that the program was designed for students with specific needs; in addition, these non-participants did not agree with or support the program.

Regarding motivation to participate in the mentoring program, responses were collected from 18 of the 20 participating respondents. Charte 1 shows the content categories identified in these responses.

\section{Chart 1}

Content of responses by participating students to an open-ended question related to motivation for participating in the mentoring program.

\begin{tabular}{|l|}
\hline CONTENT \\
\hline 1. Overcome initial difficulties related to medical school, \\
such as course content, extracurricular activities, \\
different teaching/learning methods, etc.; \\
2. Overcome initial difficulties related to psychological \\
adaptation, such as homesickness, and to get \\
acquainted with new classmates; \\
3. Discuss general social, cultural, and professional issues; \\
4. Opportunity for personal contact with teachers, \\
physicians, and other students; \\
5. Occupy lunch time; \\
6. Curiosity about a new extracurricular activity and \\
learning more about the program.
\end{tabular}

The need to overcome initial psychological or scholastic difficulties, mentioned by one-third (6/18) of respondents, constituted the most frequent response category. Responses from a few participants related to a desire to discuss general issues, socialize with peers and teachers, learn more about what was happening in the group meetings, or simply occupy spare time.

Reasons for not participating in the mentoring program were offered by 37 of the 41 non-participating students. chart 2 shows the categories of responses to this issue. Nearly half $(18 / 37)$ of these respondents mentioned lack of time due to curricular or extracurricular overload. In addition, 12 respondents explicitly mentioned lack of interest or information or failed to perceive a need to participate in the mentoring program. Very few non-participating students admitted they were unable to share personal issues with peers. 


\section{Chart 2}

Content of responses by non-participating students to an open-ended question related to reasons for not taking part in the mentoring program.

\begin{tabular}{|l|}
\hline \multicolumn{1}{|c|}{ CONTENT } \\
\hline 1. Lack of time and/or difficulties with the schedule; \\
2. Competition for students' time from more attractive \\
extracurricular activities; \\
3. Lack of interest; \\
4. Lack of information on the program; \\
5. Inability to share personal issues with the group.
\end{tabular}

\section{Mentors' perceptions}

All mentors provided answers to all the questions, and they all expressed an explicitly positive perception of the program. chart 3 shows the responses regarding motivation for enrolling in the program as a mentor.

\section{Chart 3}

Content of responses by mentors to an open-ended question related to motivation for enrolling in the mentoring program.

\section{CONTENT}

1. Help students adapt to a new environment and offer support for those experiencing difficulties;

2. Improve faculty-student relations;

3. Make a personal contribution to a program that deserves to be successful;

4. Have the possibility of working objectively on problems related to the undergraduate program;

5. Make a contribution to students' personal, social, and professional development;

6. Help students cope with day-to-day difficulties, including those related to future participation in the medical profession,

7. Make a contribution to preparing more compassionate physicians.

8. Improve students' perception of the contribution of basic sciences to clinical skills;

9. Gain insight on how undergraduate students perceive teaching in general and the institution in particular;

10. Become a better and more well-rounded teacher;

11. Explore other teaching roles;

12. Have fun working with students in an academic environment.

There was a clear predominance of reasons related to academic issues, such as "...helping students adapt to a new environment and offering support for those experiencing difficulties", which were directly related to the mentoring program's objectives. However, a few mentors expressed personal or professional reasons such as "...becoming a better and more well-rounded teacher" or "...gaining insight on how undergraduate students perceive teaching in general and the institution in particular". This aspect of the teacher's personal or professional growth dominated all the mentors' answers to the question regarding perceived gains from participating in the program, as shown in chart 4 . Chart 5 shows the response categories to the mentors' perceived problems with the program, which mainly included those related to student participation, such as "lack of punctuality" or "difficulties in motivating students toattend".

\section{Chart 4}

Content of responses by mentors to an open-ended question on perceived gains from participating in the mentoring program.

\section{CONTENT}

1. Increased knowledge on junior students' needs and expectations;

2. Opportunity to reflect on the complexity of the physician training process;

3. Closer contact with undergraduate students;

4. Introduction to otherwise unavailable reading and subject matter;

5. Professional growth in the educational field;

6. Meeting and exchanging ideas with other faculty members and physicians in the mentoring program;

7. Opportunity to reflect on the diversity of the teacher's roles.

\section{Chart 5}

Content of responses by mentors to an open-ended question on perceived problems related to the mentoring program's activities.

\section{CONTENT}

1. Difficulties in motivating students to attend;

2. Difficulties in increasing student adherence to group work;

3. Discouragement due to reduced student participation;

4. Students' lack of punctuality;

5. Anxiety associated with the perceived responsibility concerning student education;

6. Difficulties related to group dynamics;

7. Discouragement due to perceived ineffectiveness of the mentoring program;

8. Difficulties related to excessively open thematic agenda;

9. Difficulties related to excessively open mentor's roles. 


\section{DISCUSSION}

One of the reasons for introducing a mentoring program for junior students in our institution was the perception that the stressful experience of entering medical school could be counterbalanced by offering an ostensive support system extended to all individuals wishing to participate. It was acknowledged that untreated stress can lead to serious individual consequences, such as substance abuse and depression, as well as occasional dysfunctional behavior towards faculty members and patients, as pointed out by other authors ${ }^{2}$. Published data showing that first-year students are particularly vulnerable to stress ${ }^{1}$, consistent with the current perception of the local support and counseling team, were critical for designing the mentoring program so as to assist new students. These assumptions for creating the mentoring program appear to have been confirmed, since the most frequent response category to the question on motivation to enroll in the program was the need to overcome initial difficulties related to either psychological or scholastic issues.

Our results show that the current students' opinions on the mentoring program recently introduced in our institution are highly positive. This was expressed not only by students regularly attending the mentoring meetings, but also by those not enrolled or those that only attended the group meetings occasionally, a finding consistent with other published results ${ }^{15}$. Reasons underlying this positive view were not specifically investigated, but appear to be linked to the fulfilling of one of the program's main objectives, namely to support and assist students in a new personal and educational setting. Despite this apparently successful start, it is still unclear whether the mentoring program will be effective in preventing more serious emotional difficulties or mental health problems. Follow-up of the program will be needed to answer this question. Likewise, whether the program will succeed in fostering the students' personal and professional development remains to be verified on a long-term basis. This concern is consistent with data from a systematic review of the impact of medical school mentoring on participants and institutions, which concluded that the evidence to support the perception of benefit is not strong, so that further research on the issue is needed $^{18}$.

The mentors' perceptions of the program were also highly positive, which was not surprising, since criteria for recruiting faculty members and medical staff for the mentor's role included high degrees of both motivation and commitment to the undergraduate medical program. Accordingly, most of the reasons cited by mentors for joining the mentoring program (chart 3) appear to confirm these expectations.
One interesting and important finding of our study was the mentors' perceptions that engaging in the mentoring program's activities was useful not only to help students, but also to foster their own personal and professional development. This appears to be achieved in a variety of ways (chart 4), including increased knowledge of students' needs, sharing with other mentors, and reflection on the teacher's roles. This mutually beneficial arrangement was highlighted in a recent review ${ }^{19}$ and had also been reported previously by Murphy (2003), who proposed an original "reverse mentoring project" ${ }^{20}$. Nevertheless, the impact of mentoring on faculty development has not been extensively stressed by other authors ${ }^{7,12,14}$.

Meanwhile, perceptions by both students and mentors indicated that specific measures are needed to improve the program. These measures include specific strategies to provide students with more precise information on the program's objectives, besides encouraging enrolled students to attend more regularly and to participate more actively in the group meetings. Organizational aspects (on the institutional side) also need to be approached, which would include negotiating the program into the regular curriculum so as to both reduce student overload and create free time slots for mentoring activities. Nevertheless, there is a subgroup of students who will never show the need for (or the interest in) participating in mentoring activities. This is indicated by some opinions from non-participating students, consistent with other authors' findings ${ }^{13}$.

The mentors' training and supervisory activities also need to be improved, in order to enhance their skills and allow them to gain increased awareness of their role in the institutional context $\mathrm{t}^{21}$. This training and supervision should include not only improved skills in conducting group activities and dealing with students experiencing emotional difficulties, but also the development of student evaluation skills, which would lead to increased program quality ${ }^{21}$. Measures are also needed to reward mentors, since the current program does not provide either financial compensation or institutional credit for mentors' participation.

As exploratory research, our study has a number of limitations. The proportion of participants answering the questionnaire was relatively low and may have biased the results towards a positive assessment of the mentoring program. Perceptions by both students and mentors could also be investigated in greater depth, using more accurate methods like interviews or focus groups. This could lead to clarification of some issues that were not explored in this study, such as the differential role of mentors, senior students, and peer mentees on the participants' perceptions. The impact of the supervisory committee on the 
mentors' perceptions could also be addressed. Nevertheless, besides providing useful data for the local quality assurance process, the present study's findings indicated that this kind of initiative has a positive impact on the educational setting and may benefit not only new students but also faculty members that participate as mentors.

\section{CONCLUSION}

This short-term report on a recently introduced, group-based mentoring program designed to assist junior medical students indicates that both participating and non-participating students shared positive opinions of the program and highlighted the mentors' supportive role, viewed as facilitating adaptation to a new setting. Faculty members and staff physicians were also satisfied with mentoring in the program, which appeared to meet their expectations. In particular, mentors acknowledged that participating in the program was a useful way of fostering their own personal and professional development.

\section{REFERENCES}

1. Dahlin M, Joneborg N, Runeson B. Stress and depression among medical students: a cross-sectional study. Med Educ. 2005; 39:594-604.

2. Dyrbye LN, Thomas MR, Shanafelt TD. Medical student distress: causes, consequences, and proposed solutions. Mayo Clin Proc. 2005; 80:1613-1622.

3. Fernandez JM, Cianflone ARL. O núcleo de apoio psicopedagógico da Faculdade de Medicina de Ribeiräo Preto USP. Medicina (Ribeirão Preto). 1991; 24: 122-7.

4. Nogueira-Martins LA, Fagnani Neto R, Macedo PC, Citero VA, Mari JJ. The mental health of graduate students at the Federal University of Sao Paulo: a preliminary report. 0;Braz J Med Biol Res. 2004; 37:1519-1524.

5. Bellodi PL. Retaguarda Emocional Para o Aluno de Medicina da Santa Casa de São Paulo (REPAM): realizações e reflexões. Rev Bras Educ Med. 2007: 31: 5-14.

6. Milan LR, Arruda PCV. Psychological assistance to medical students: 21 years of experience. Rev Assoc Med Bras. 2008; 54: 90-94.

7. Rodolfa E, ChavoorS, VelasquezJ. Informal mentoring between faculty and medical students. JAMA. 1995;274:1396-1397.

8. Ramanan RA, Phillips RS, Davis RB, Silen W, Reede JY. Counseling services at the University of California, Davis: helping medical students cope. Am J Med. 2002;112:336-341.

9. Bellodi PL, Martins MA. Tutoria: mentoring na formação médica. São Paulo: Casa do Psicólogo; 2005.
10. Rose GL, Rukstalis MR, Schuckit MA. Towards effective mentoring in general practice. Br J Gen Pract. 1997;47:457-460.

11. Taherian K, Shekarchian M. Mentoring for doctors. Do its benefits outweigh its disadvantages? Med Teach. 2008;30:e95—e99.

12. Mann MP. Faculty mentors for medical students: a critical review. Med Teach. 1992;14: 311-319.

13. Cottrell DJ, McCrorie P, Perrin F. The personal tutor system: an evaluation. Med Educ. 1994;28:544-549.

14. Rose GI, Rustaklis MR, Schukit MA. Informal mentoring between faculty and medical students. Acad Med. 2005;80:344-348.

15. Hauer KE, Teherani A, Dechet A, Aagaard EM. Medical students' perceptions of mentoring: a focus-group analysis. Med Teach. 2005;27:732-734.

16. Abernethy AD. A mentoring program for underrepresented-minority students at the University of Rochester School of Medicine. Acad Med. 1999;74:356-359.

17. Kalet A, Krackov S, Rey M. Mentoring for a new era. Acad Med. 2002;77:1171-1172.

18. Sambunjak D, Straus SE, Marusic A. Mentoring in Academic Medicine: a Systematic Review. JAMA. 2006;296:1103-1115.

19. Botti SHO, Rego S. Preceptor, supervisor, tutor e mentor: quais são seus papéis? Rev Bras Educ Med. 2008: 363-373.

20. Murphy J. Can medical students teach senior doctors? Report on a unique reverse mentoring project. [acessed in: dec.2003]. Avallable from: http:/ /www.londondeanery.ac.uk.

21. Ramani S, Gruppen L, Kachur EK. Twelve tips for developing effective mentors. Med Teach. 2006;28:404-408.

This work received financial support from the local foundation FAEPA/HCFMRPUSP.

\section{AUTHORS' CONTRIBUTIONS}

The authors participated sufficiently in the conception and design of this study and in the amalysis and interpretation.

\section{DISCLOSURE}

The authors hereby declare that they have no conflicts of interest

\section{MAILING ADDRESS}

Luiz E. A. Troncon

Departamento de Clínica Médica, Hospital das Clínicas - USP

Bairro - Ribeirão Preto

CEP.14048-900 SP, Brazil

E-mail: ledatron@fmrp.usp.br 